\title{
Large Cervical Vagus Nerve Tumor in a Patient with Neurofibromatosis Type 1 Treated with Gross Total Resection: Case Report and Review of the Literature
}

\author{
${ }^{1}$ Department of Neurological Surgery, Columbia University, New York, \\ New York, United States \\ 2 Department of Neurological Surgery, University of California, \\ San Francisco, California, United States \\ ${ }^{3}$ Department of Neuroradiology, University of California, \\ San Francisco, California, United States
}

David P. Bray ${ }^{1, *} \quad$ Andrew K. Chan ${ }^{2, *} \quad$ Cynthia T. Chin ${ }^{3}$ Line Jacques ${ }^{2}$

\begin{abstract}
Address for correspondence Andrew K. Chan, MD, Department of Neurological Surgery, University of California, San Francisco, 505 Parnassus Avenue, M780, San Francisco, CA 94143, United States (e-mail: andrew.chan@ucsf.edu).
\end{abstract}

J Brachial Plex Peripher Nerve Inj 2016;11:e48-e54.
Abstract
Keywords
- vagus nerve tumor
- cervical vagus nerve
- neurofibromatosis type 1
- neurofibroma
- neck mass
- diffusion tensor imaging

Neurofibromas are benign peripheral nerve sheath tumors that occur commonly in individuals with neurocutaneous disorders such as neurofibromatosis type 1. Vagal nerve neurofibromas, however, are a relatively rare occurrence. We present the case of a 22-year-old man with neurofibromatosis type 1 with a neurofibroma of the left cervical vagal nerve. The mass was resected through an anterior approach without major event. In the postoperative course, the patient developed left vocal cord paralysis treated with medialization with injectable gel. We then present a comprehensive review of the literature for surgical resection of vagal nerve neurofibromas.

\section{Introduction}

Neurofibromas are benign peripheral neural sheath tumors composed of Schwann cells, fibroblast-like cells, and perineurial-like cells. ${ }^{1-3}$ They can occur in a sporadic fashion, or in association with a genetic neurocutaneous disorder such as neurofibromatosis type 1 (NF1), formerly referred to as von Recklinghausen disease. NF1 is an autosomal dominant genetic disease and is estimated to occur in 1 per 3,000 to 4,000 individuals. $^{1,4,5}$ Neurofibromas that are associated with NF1 are thought to arise from loss of NF1 gene expression from the long arm of chromosome 17 (17q) which leads to increased levels of activated RAS. ${ }^{1,2}$ Activated RAS is an oncogene which promotes unregulated growth. Loss of NF1 leads to increased occurrence of neurofibromas and optic gliomas, as well as pathognomonic findings of pigmented nodules of the iris (Lisch nodules) and pigmented skin lesions (café au lait spots).

\footnotetext{
David P. Bray and Andrew K. Chan contributed equally into this article.
}

DOI http://dx.doi.org/ 10.1055/s-0036-1594010. ISSN $1749-7221$.
Here we present the rare case of a large vagus nerve neurofibroma that was resected in a patient with NF1. We present the case report of the patient, including imaging findings and a technical note of a gross total resection (GTR). We also provide a review of the literature, including a discussion on the treatment algorithm of a patient with a vagus nerve neurofibroma.

\section{Case Description}

\section{History and Examination}

The patient is a 22-year-old man with a history of NF1 and more than 25 previous neurofibroma resections including a left below-the-knee amputation who presented with a growing mass in his left anterior neck. He first noticed the mass 5 years ago and noted that it has been steadily growing during that time. The mass was associated with mild discomfort and tenderness. He was without dysphagia, dysphonia, hearing changes, or other cranial nerve and brachial plexus symptoms.

Physical examination revealed a large left anterior cervical mass that was tender, hard, and not mobile to palpation.
License terms

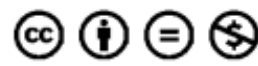

(c) 2016 Georg Thieme Verlag KG Stuttgart · New York accepted

October 4, 2016 

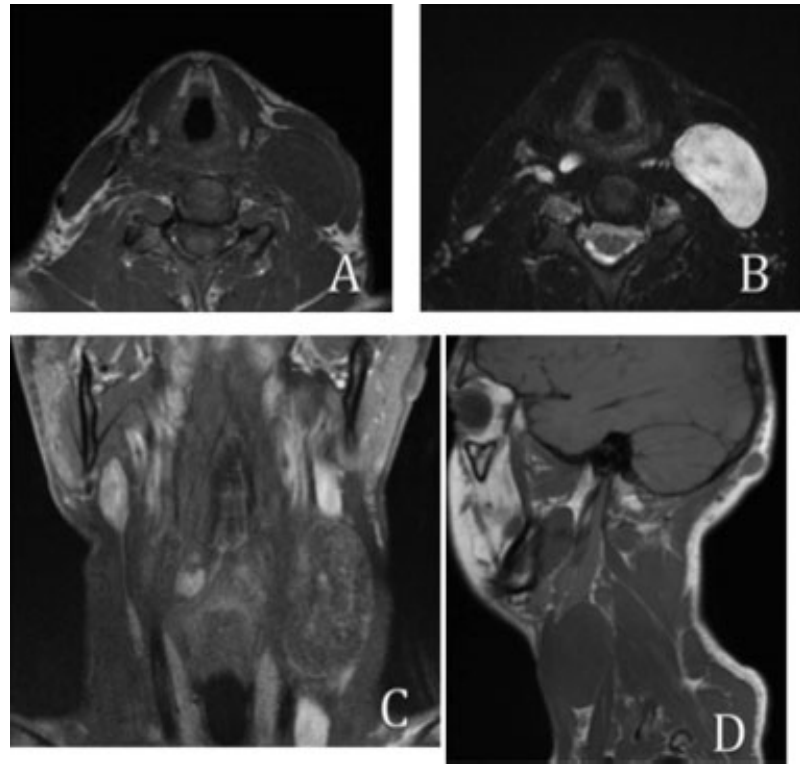

Fig. 1 Preoperative magnetic resonance imaging from left, right, to below: (A) Axial T1 without contrast shows isointense mass; (B) Axial T2 shows hyperintense mass; (C) Coronal T1 with contrast shows heterogeneously enhancing mass; (D) Sagittal T1 without contrast shows isointense mass.

\section{Neuroimaging}

Magnetic resonance imaging (MRI) with and without gadolinium contrast revealed a well-circumscribed, T2 hyperintense, T1 isointense mass deep to the left sternocleidomastoid muscle (SCM) ( - Fig. 1). The mass demonstrated heterogenous contrast enhancement and was measured to be $2.6 \times 4.4 \times 6.2 \mathrm{~cm}$.
Diffusion imaging demonstrated a mass with an apparent diffusion coefficient (ADC) of $2 \times 10^{-3} \mathrm{~mm}^{2} / \mathrm{sec}$ (-Fig. 2). Imaging was consistent with a neurofibroma.

In addition to the left cervical mass, there were innumerable smaller T2 hyperintense, avidly enhancing lesions throughout the superficial and deep soft tissues of the neck consistent with neurofibromas.

Because of concern for progressive increase in size of the mass, patient discomfort, cosmetic appearance, and diagnosis purposes, we proceeded with surgical resection. Otolaryngology was consulted and assisted with the neck dissection.

\section{Operation}

After induction with general endotracheal anesthesia, the patient was placed in the supine position. The endotracheal tube was fit with the neural integrity monitor EMG (NIM-Response 3.0 System; Medtronic, Jacksonville, FL). Other electrodes for neuromonitoring were applied by the electrophysiologist. The anterior left neck was prepped and sterilized in the usual fashion. A shoulder roll was placed, and a horizontal skin incision was marked (-Fig. 3). The neck was injected with $3 \mathrm{~mL}$ of lidocaine with epinephrine. The superficial skin incision was made with a 5 blade, and subplatysmal skin flaps were elevated superiorly to the mandible and inferiorly to the clavicle.

The mass was palpated anteriorly and deep to the SCM. The external jugular vein (EJV) was preserved along with the greater auricular nerve. The SCM was elevated along its lateral surface and the omohyoid identified. The internal jugular vein (IJV) was identified and the carotid artery was palpated deep

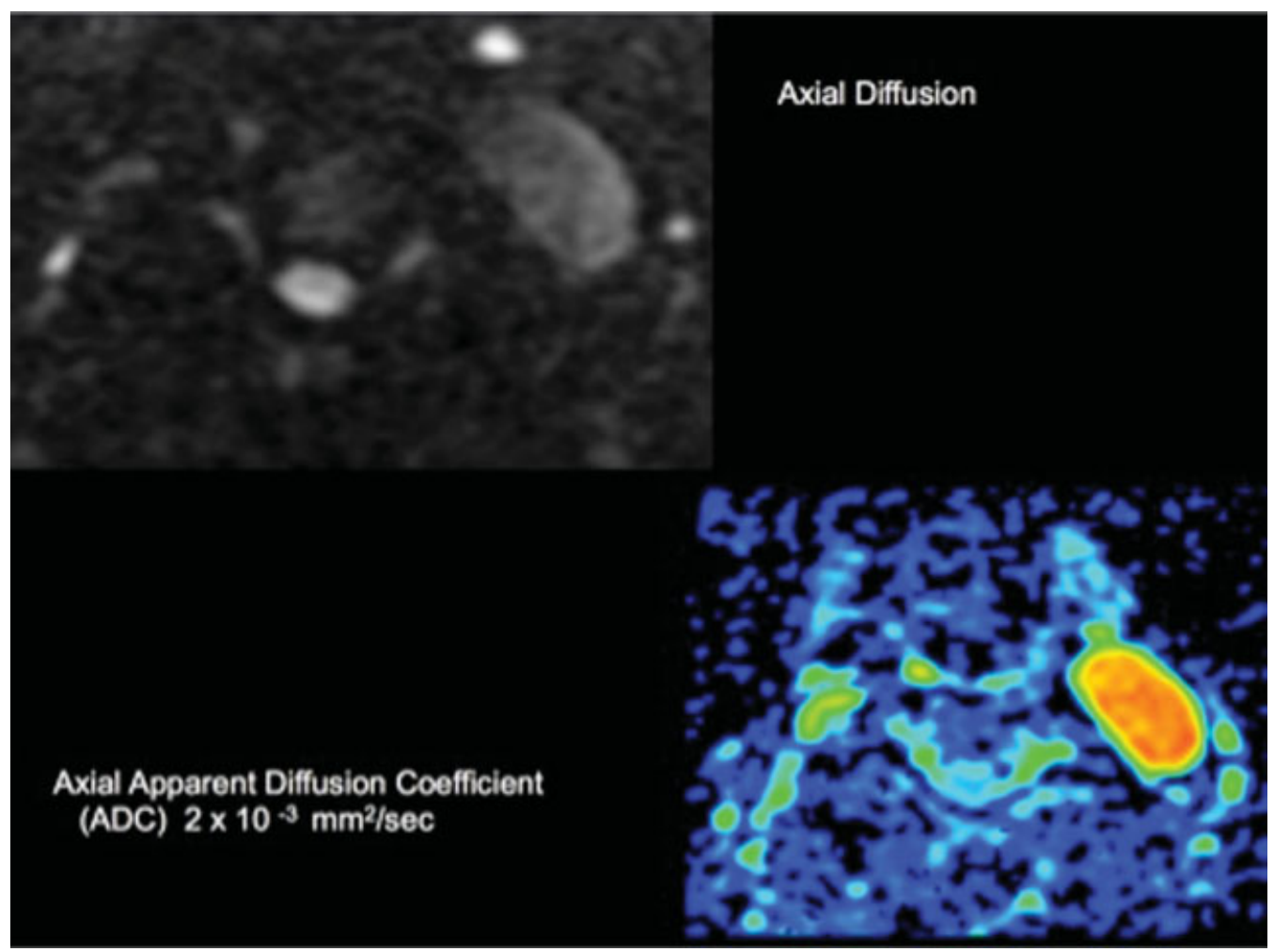

Fig. 2 Preoperative magnetic resonance imaging: axial diffusion-weighted imaging (DWI) and apparent diffusion coefficient (ADC) map through the left vagal neurofibroma demonstrate increased signal on DWI with relative increased diffusivity on the ADC map measuring $2 \times 10^{-3} \mathrm{~mm}^{2} / \mathrm{sec}$. 


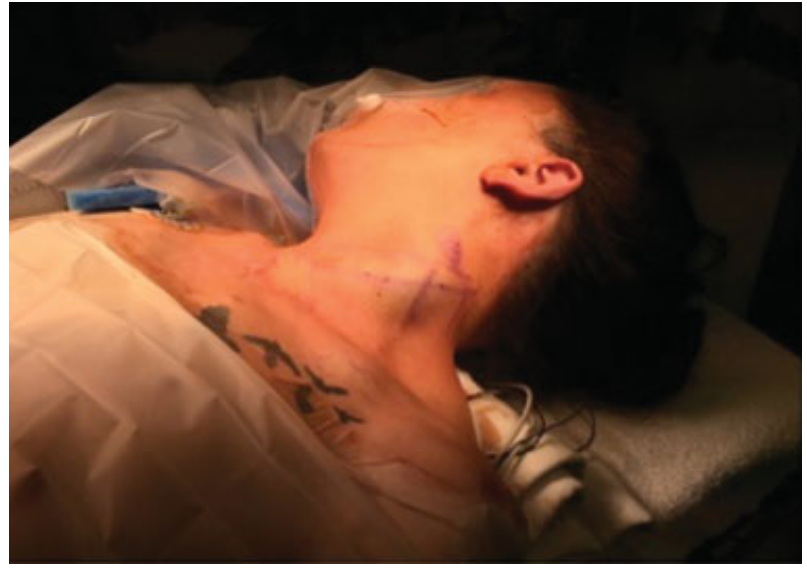

Fig. 3 Patient positioning: The patient is supine and marked for an oblique anterior neck incision.

and medial to the mass. The mass was greatly displacing the vessels around it, including the IJV, which was distended.

The mass was dissected along its posterior border and an attempt was made to identify the cranial nerve $(\mathrm{CN}) \mathrm{XI}$; CN XII was above the superior edge of the mass. The mass was dissected down to the prevertebral muscles and off of the deep cervical fascia. The inferior aspect of the tumor was identified and was connected to a nerve travelling along the EJV and IJV. This nerve was stimulated and was found to be the vagus nerve with stimulation of the laryngeal muscles on the NIM EMG.

Next, the great vessels were isolated off the mass with gentle dissection along the IJV and the carotid artery. The vessels were freed from the base of the mass and then from the superior edge of the mass. The final remaining fascial attachments were freed and the tumor capsule was identified ( - Fig. 4).

The tumor was resected while preserving the vagal nerve. One branch going to the tumor was not functional (determined by stimulation) and was removed. We were able to stimulate at $0.5 \mathrm{mV}$ and had a strong response of the laryn-

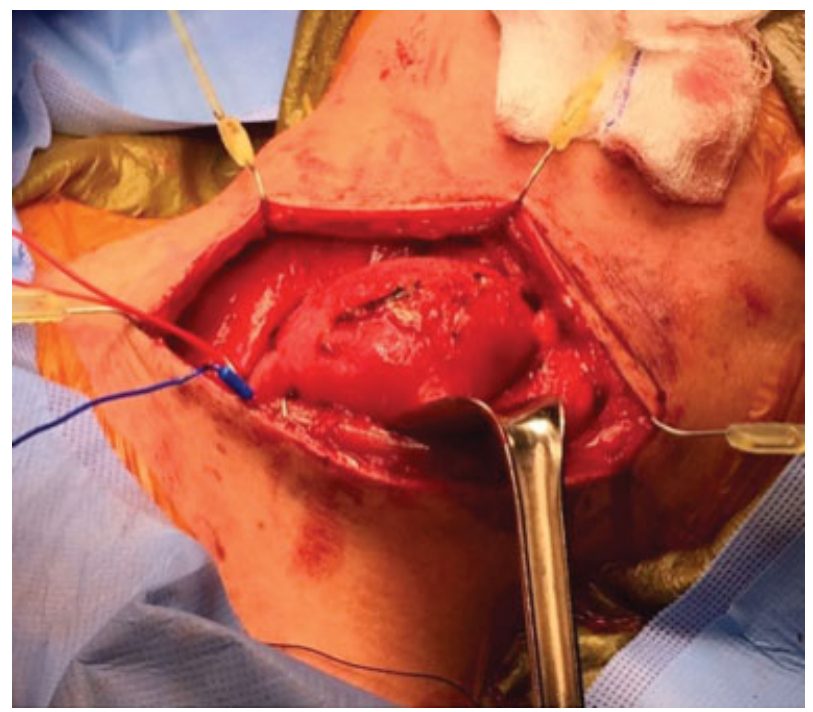

Fig. 4 Vagus nerve tumor mass visualized after wide anterior neck dissection. The sternocleidomastoid muscle is retracted laterally. geal musculature prior to resection of the tumor. However, the preserved nerve was not able to be stimulated at $1.5 \mathrm{mV}$ at the end of the resection. Elements of the removed tumor were sent to the pathology laboratory for permanent assessment. The mass was consistent with a myxoid, cystic neurofibroma, without areas of hemorrhage, necrosis, or induration (-Figs. 5 and $\mathbf{6}$ ). The resection cavity was inspected for residual tumor and it was concluded that a near GTR was achieved (-Fig. 7). A Jackson-Pratt drain was placed in the inferior neck and under the SCM. The platysma was closed with 3-0 vicryl and the skin with 4-0 subcuticular monocryl.

\section{Postoperative Course}

The patient noted a change in the quality of his voice after surgery that had not improved by his 1-month postoperative office visit. He noted intermittent coughing and choking with swallowing while supine. He had no difficulty swallowing while sitting upright. He was frustrated with the quality of his voice and felt that he could not be heard clearly over the phone.

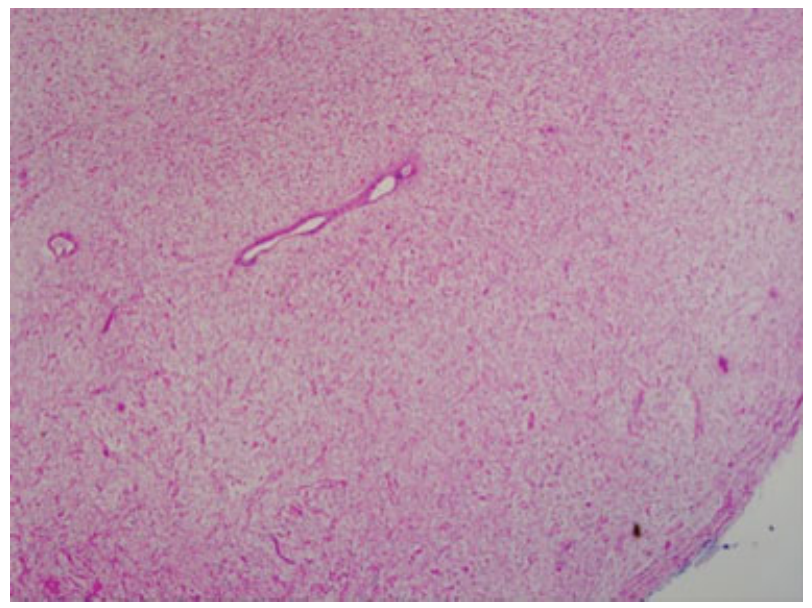

Fig. 5 Hematoxylin and eosin stain of resected mass. Findings consistent with a myxoid, cystic neurofibroma, without areas of hemorrhage, necrosis, or induration ( $\times 10$ magnification).

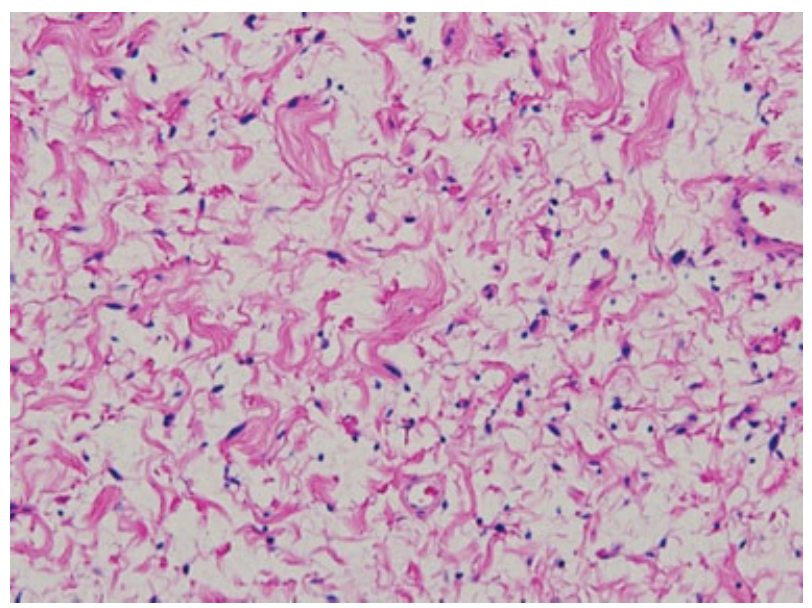

Fig. 6 Hematoxylin and eosin stain of resected mass, magnified. Wirelike collagen resembles "shredded carrots" ( $\times 40$ magnification). 


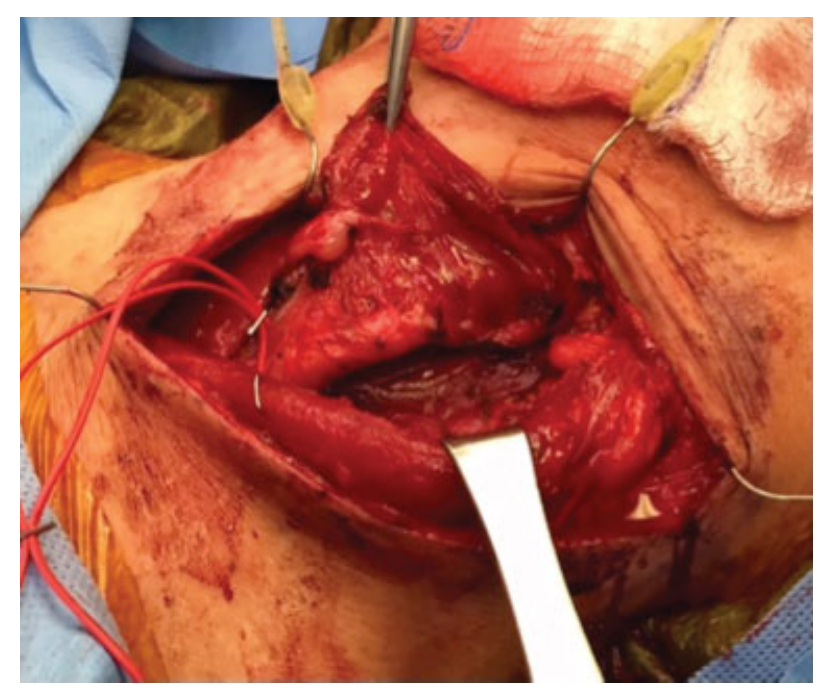

Fig. 7 Vagus nerve tumor resected. Vagus nerve tumor with nearly gross total resection. Sternocleidomastoid muscle retracted laterally.

Laryngoscopy 1-month postoperative confirmed a left vocal cord paralysis. He was scheduled to receive medialization of the left vocal cord with Prolaryn Gel (Merz North America, Inc., Raleigh, North Carolina (NC), USA).

\section{Discussion}

Neoplasms of the vagus nerve are rare. Most of our literature on the subject of epidemiology and management of these lesions is composed of case studies and series. Within these series, the majority of neoplasms of the vagus nerve are schwannomas. $^{\text {6-11 }}$

Neurofibromas can theoretically arise from any peripheral nerve. It is thought that approximately $25 \%$ of symptomatic neurofibromas occur in the head and neck region. ${ }^{12}$ Occasionally, they can cause cranial neuropathies by direct compression on CN IX, XI, and XII or a Horner syndrome via superior cervical ganglion compression. 6,8,13,14 They are generally asymptomatic until they are large enough to cause discomfort or disfigurement. About one-half of neurofibromas present with pain. ${ }^{3,7}$ Vagus nerve tumors can present with dysphagia. ${ }^{15}$ One case study of a vagus nerve sheath tumor described percussion of the mass causing a cough. 7,16 Most studies of vagus nerve neurofibromas have not borne out a sex-related predilection for occurrence. Peetermans et $\mathrm{al}^{12}$ found that the age occurrence of vagus nerve neoplasms followed a bimodal distribution with peaks at the ages of 33 and 55. Physical exam maneuvers that are characteristic of peripheral nerve sheath tumors are a laterally mobile mass that cannot be manipulated superiorly or inferiorly. While the overwhelming majority of neurofibromas of the head and neck are benign, slow-growing tumors, it has been reported that they can degenerate into becoming malignant masses. ${ }^{17}$ Interestingly, a major risk factor for the development of malignant peripheral nerve sheath tumors in the head and neck is an antecedent history of radiation. ${ }^{17}$
The management of a neurofibroma in a patient with NF1 should differ from the management of a patient with a spontaneous nerve sheath tumor. First, neurofibromas occur with greater prevalence in individuals with NF1, vis-à-vis schwannomas, which are the most common neoplasms of the vagal nerve. Dabir et al studied intrathoracic vagal nerve tumors and found that $28 \%$ of all tumors were associated with NF1. ${ }^{18}$ Histological examination determined that all NF1 intrathoracic vagal nerve tumors were neurofibromas. Second, patients with NF1 generally have multiple nerve sheath tumors. Indeed, as McClatchey lamented in his review of neurofibromatosis, the true challenge in managing patients with NF1 is the "sheer multiplicity of tumors."2 Fifty-four percent of individuals with the NF1 diagnosis have one or more neurofibromas. ${ }^{19}$ Our patient is representative of this problem as he had at least 25 prior surgeries for neurofibromas by the age of 22 years. It is generally advised to delay surgery for excision of neurofibromas unless they are rapidly growing or are symptomatic due to size or compression on other neurovascular structures.

Additionally complicating the surgical management of NF1 neurofibromas, patients with NF1 have a higher prevalence of developing plexiform neurofibromas. Case series demonstrate that 27 to $43 \%$ of patients with NF1 will develop neurofibromas of the plexiform variety. ${ }^{19-22}$ While schwannomas and sporadic localized neurofibromas tend to be either encapsulated or circumscribed, plexiform neurofibromas involve multiple fascicles of the same nerve and are more diffuse in nature. ${ }^{1}$ Plexiform neurofibromas tend to be infiltrative and grow along tissue planes. ${ }^{7,23}$ They often cannot be completely excised without sacrifice of much of the nerve and therefore resection can lead to significant loss of neurological function. ${ }^{7,23}$ An obvious solution to this dilemma is to leave behind remnants of tumor that cannot be resected without sacrificing neurological function; however, neurofibromas in patients with NF1 have a rate of 10 to $15 \%$ malignant degeneration. ${ }^{7,23-25}$ Studies have suggested that 50 to $60 \%$ of malignant peripheral nerve sheath tumors observed in clinical practice are associated with patients with NF1. These tumors have high morbidity and high rates of reoccurrence if GTR is not achieved. ${ }^{26-29}$

Often, clinicians tend to approach any mass in the neck as "malignant until proven otherwise." Ultrasonography can be helpful in the initial assessment of a suspicious neck mass due to its availability, ease of use, and real-time results it provides. ${ }^{30}$ Additionally, the dynamic nature of the ultrasound imaging modality can let the surgeon determine the interaction of the mass with surrounding neurovascular components. If a peripheral nerve sheath tumor is suspected by history and physical exam/ultrasound findings, it is reasonable to pursue MR imaging of the mass. MRI is accepted as the best imaging modality to characterize peripheral nerve sheath tumors. ${ }^{31,32}$ As demonstrated with this case report, neurofibromas are usually $\mathrm{T} 1$ isointense, $\mathrm{T} 2$ hyperintense, and heterogeneously enhancing on T1 post-gadolinium contrast. ${ }^{31,32}$ In at least one prospective trial, MR diffusion tensor imaging (DTI) has allowed for direct visualization of specific nerve tracts entering and leaving a peripheral nerve sheath tumor. ${ }^{33}$ 
Benign and malignant primary nerve sheath tumors demonstrate overlapping features on MR imaging, including T2 hyperintensity, focal enlargement, and enhancement. ${ }^{34,35}$ Diffusivity measurements from diffusion-weighted imaging (DWI) may be helpful in differentiating malignant and benign peripheral nerve sheath tumors. ${ }^{36}$

Diffusivity, or microscopic mobility of water protons in tissue, inversely correlates with tumor cellularity and tumor grade in general. ${ }^{36}$ The ADC is a measure of the diffusivity. Statistically significant differences in mean ADC values have been demonstrated between benign and malignant peripheral nerve lesions with malignant lesions demonstrating $\mathrm{ADC} \leq 1.08 \times 10^{-3} \mathrm{~mm}^{2} / \mathrm{sec}$, and benign lesions demonstrating $A D C \geq 1.30 \times 10^{-3} \mathrm{~mm}^{2} / \mathrm{sec}^{37}$ The relatively high ADC value of this particular vagal nerve neurofibroma $\left(2 \times 10^{-3} \mathrm{~mm}^{2} / \mathrm{sec}\right)$ was supportive of benign histology, correlating with the final pathology.

The difference in ADC values may reflect tumor cellularity, integrity of cell membranes, nuclear-to-cytoplasmic ratio, and water content of the extracellular matrix. These features have been postulated to account for relatively low diffusivity within malignant solid tumors in prior studies. ${ }^{38,39}$

As mentioned previously, the gold-standard treatment for a symptomatic vagus nerve tumor is an attempt for GTR with preservation of neurological function as radiosurgery is not effective on these tumors. ${ }^{7,8,23,40}$ Neurofibromas often prove to be the most difficult nerve sheath tumors to achieve GTR. ${ }^{41}$ Surgery for resection of a vagus tumor mass should be a multiple disciplinary endeavor. ${ }^{15}$ In our case, both otolaryngologists and neurosurgeons were employed to treat this tumor in a complicated anatomical area. Otolaryngologists performed a large neck dissection in our patient to create a wide operative field, which is critical to avoid injury to the important neurovascular structures that traverse the anatomical area. While imaging can help with diagnosis and inform safe operative corridors for the surgeon, electromyography (EMG) for nerve action potentials (NAP) must be used intraoperatively for safe tumor resection. ${ }^{42}$ In our case, after the tumor mass was visualized following the neck dissection, NAP was used to identify on which nerve the tumor was

Table 1 Cervical vagus nerve neurofibromas treated with resection

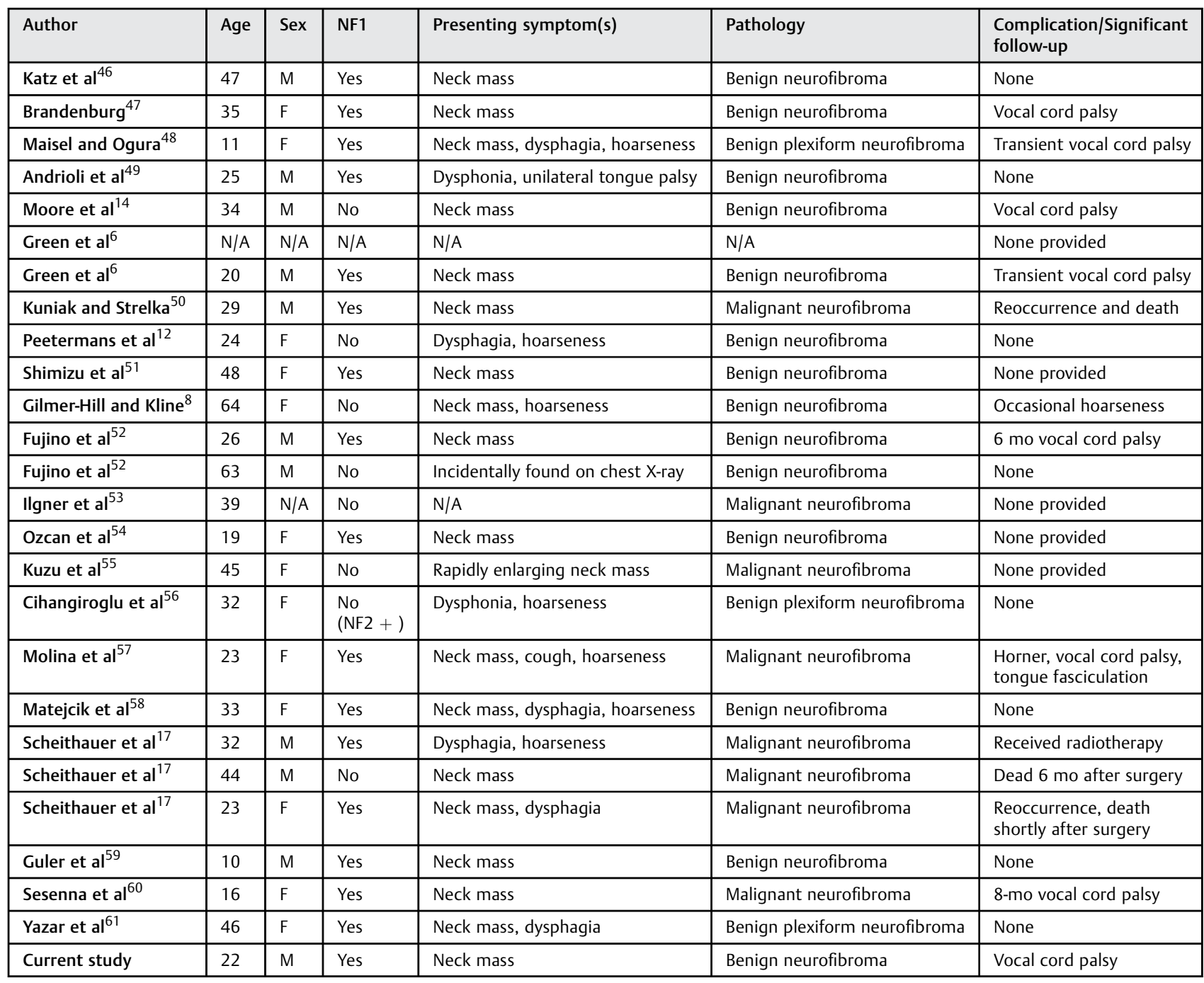


attached. NAP was assessed throughout the operation to delineate which nerve fascicles were nonfunctional, and therefore appropriate to sacrifice.

While schwannomas have one entering and one leaving fascicle to the tumor mass, allowing for fascicle excision, neurofibromas have multiple fascicles travelling to and from the tumor mass. Many different approaches have been advocated for the treatment of neurofibromas, from a trial of watchful waiting ${ }^{43}$ to en bloc excision with end-to-end nerve grafting. ${ }^{44}$ Donner et al advised for the surgical treatment of intracapsular enucleation for neurofibromas. ${ }^{7}$ This technique was employed in treating the patient in this case study. The tumor capsule should be longitudinally incised and entered. Microsurgical techniques should be used to meticulously separate each fascicle from tumor. Gentle retraction on surrounding fascicles is applied to delicately remove the tumor mass from viable nerve. NAP is consulted throughout the case to ensure preservation of neurological function. Resected tumor should be sent for histopathological evaluation during the operative case. If the tumor is determined to be benign, surgeons should strike a balance between preserving neurological function and achieving GTR. Using this technique, we were able to accomplish a near GTR for this patient.

Possible complications from vagus nerve neurofibroma resection surgery include injury to important neurovascular structures in the neck, especially injury to the vagus nerve. This could lead to vocal cord paralysis, arrhythmias, and dysphagia. In their large series that included neurofibroma resections in NF1 patients with multifocal nerve lesions, Donner et al reported a $16 \%$ decrease in motor function using the intracapsular enucleation technique. Up to $10 \%$ of these patients developed pain syndromes in the sensory distribution associated with the nerve that was operated upon. ${ }^{7}$ Green et al reported a $40 \%$ occurrence of dysphagia and $46 \%$ occurrence of aspiration after vagus nerve tumor surgery. ${ }^{6}$ Gilmer-Hill and Kline stated that nearly all patients who have vagus nerve tumor resections will develop transient hoarseness postoperatively. ${ }^{8}$ Our patient noticed a change in voice that did not resolve within a month postoperatively. Laryngoscopic examination revealed a paralyzed left vocal cord which was treated with injection of Prolaryn Gel. At least one study has shown that by 12 months after injection laryngoplasty, $71 \%$ of patients experienced at least compensated function of the paralyzed vocal cord. ${ }^{45}$

- Table 1 shows cervical vagus nerve neurofibromas treated with surgical resection. A PubMed search was completed using search terms "vagus(al) nerve neurofibroma" and "vagus(al) nerve neurilemmoma" from March 1947 to October 2015. Cases of histologically confirmed neurofibromas arising from the cervical level of the vagus nerve (angle of mandible to sternoclavicular joint) were included from English-written abstracts and articles that were retrievable through PubMed. Cases that did not have adequate demographic/histologic information were not translated into English, or were not retrievable through PubMed were not included.
This search found 25 other reported cervical vagus nerve neurofibromas in the literature. The average age of presentation in these cases was 32.8 ( \pm 14.2 ) years. Sixty percent of patients had NF1; 75\% of patients presented with a neck mass; and $46 \%$ had dysphagia, hoarseness, or another neurological deficit. After surgery, $45 \%$ of patients developed at least transient vocal cord palsy. It appears that postoperative hoarseness and vocal paralysis occur at a relatively high rate after vagus nerve neurofibroma resection, and patients should be counseled about this outcome.

\section{Conclusion}

Vagus nerve neurofibromas are rare, but are more common in patients with NF1. Gold-standard treatment of symptomatic benign vagus nerve masses is an attempt at GTR with minimal loss of nerve function. Postoperative hoarseness and vocal paralysis are difficult to avoid in vagus nerve neurofibroma resection.

\section{Source of Funding}

None.

\section{References}

1 Kumar V, Abbas AK, Aster JC, Robbins SL. Robbins Basic Pathology. 9th ed. Philadelphia, PA: Elsevier/Saunders; 2013

2 McClatchey AI. Neurofibromatosis. Annu Rev Pathol 2007; 2:191-216

3 Marocchio LS, Oliveira DT, Pereira MC, Soares CT, Fleury RN. Sporadic and multiple neurofibromas in the head and neck region: a retrospective study of 33 years. Clin Oral Investig 2007;11(2): 165-169

4 Friedman JM. Epidemiology of neurofibromatosis type 1. Am J Med Genet 1999;89(1):1-6

5 Packer RJ, Gutmann DH, Rubenstein A, et al. Plexiform neurofibromas in NF1: toward biologic-based therapy. Neurology 2002; 58(10):1461-1470

6 Green JD Jr, Olsen KD, DeSanto LW, Scheithauer BW. Neoplasms of the vagus nerve. Laryngoscope 1988;98(6, Pt 1):648-654

7 Donner TR, Voorhies RM, Kline DG. Neural sheath tumors of major nerves. J Neurosurg 1994;81(3):362-373

8 Gilmer-Hill HS, Kline DG. Neurogenic tumors of the cervical vagus nerve: report of four cases and review of the literature. Neurosurgery 2000;46(6):1498-1503

9 Chang SC, Schi YM. Neurilemmoma of the vagus nerve. A case report and brief literature review. Laryngoscope 1984;94(7): 946-949

10 St Pierre S, Theriault R, Leclerc JE. Schwannomas of the vagus nerve in the head and neck. J Otolaryngol 1985;14(3):167-170

11 Kline DG, Hudson AR. Nerve Injuries: Operative Results for Major Nerve Injuries, Entrapments, and Tumors. 1st ed. Philadelphia, PA: W.B. Saunders; 1995

12 Peetermans JF, Van de Heyning PH, Parizel PM, et al. Neurofibroma of the vagus nerve in the head and neck: a case report. Head Neck 1991;13(1):56-61

13 Persson AV, Frusha JD, Dial PF, Jewell ER. Vagal body tumor: paraganglioma of the head and neck. CA Cancer J Clin 1985; 35(4):232-237

14 Moore G, Yarington CT Jr, Mangham CA Jr. Vagal body tumors: diagnosis and treatment. Laryngoscope 1986;96(5):533-536 
15 Latham K, Buchanan EP, Suver D, Gruss JS. Neurofibromatosis of the head and neck: classification and surgical management. Plast Reconstr Surg 2015;135(3):845-855

16 Park CS, Suh KW, Kim CK. Neurilemmomas of the cervical vagus nerve. Head Neck 1991;13(5):439-441

17 Scheithauer BW, Erdogan S, Rodriguez FJ, et al. Malignant peripheral nerve sheath tumors of cranial nerves and intracranial contents: a clinicopathologic study of 17 cases. Am J Surg Pathol 2009; 33(3):325-338

18 Dabir RR, Piccione W Jr, Kittle CF. Intrathoracic tumors of the vagus nerve. Ann Thorac Surg 1990;50(3):494-497

19 Friedman JM, Birch PH. Type 1 neurofibromatosis: a descriptive analysis of the disorder in 1,728 patients. Am J Med Genet 1997; 70(2):138-143

20 Créange A, Zeller J, Rostaing-Rigattieri S, et al. Neurological complications of neurofibromatosis type 1 in adulthood. Brain 1999;122(Pt 3):473-481

21 Riccardi VM. Neurofibromatosis: Phenotype, Natural History, and Pathogenesis. 2nd ed. Baltimore, MD: Johns Hopkins University Press; 1992

22 Huson SM, Harper PS, Compston DA. Von Recklinghausen neurofibromatosis. A clinical and population study in south-east Wales. Brain 1988;111(Pt 6):1355-1381

23 Kim DH, Murovic JA, Tiel RL, Moes G, Kline DG. A series of 397 peripheral neural sheath tumors: 30 -year experience at Louisiana State University Health Sciences Center. J Neurosurg 2005;102(2): 246-255

24 Pacelli J, Whitaker $\mathrm{CH}$. Brachial plexopathy due to malignant peripheral nerve sheath tumor in neurofibromatosis type 1 : case report and subject review. Muscle Nerve 2006;33(5):697-700

25 McGaughran JM, Harris DI, Donnai D, et al. A clinical study of type 1 neurofibromatosis in north west England. J Med Genet 1999; 36(3):197-203

26 Ducatman BS, Scheithauer BW, Piepgras DG, Reiman HM, Ilstrup DM. Malignant peripheral nerve sheath tumors. A clinicopathologic study of 120 cases. Cancer 1986;57(10):2006-2021

27 Hruban RH, Shiu MH, Senie RT, Woodruff JM. Malignant peripheral nerve sheath tumors of the buttock and lower extremity. A study of 43 cases. Cancer 1990;66(6):1253-1265

28 Kourea HP, Bilsky MH, Leung DH, Lewis JJ, Woodruff JM. Subdiaphragmatic and intrathoracic paraspinal malignant peripheral nerve sheath tumors: a clinicopathologic study of 25 patients and 26 tumors. Cancer 1998;82(11):2191-2203

29 Woodruff JM. Pathology of tumors of the peripheral nerve sheath in type 1 neurofibromatosis. Am J Med Genet 1999;89(1):23-30

30 Giovagnorio F, Martinoli C. Sonography of the cervical vagus nerve: normal appearance and abnormal findings. AJR Am J Roentgenol 2001;176(3):745-749

31 Singh T, Kliot M. Imaging of peripheral nerve tumors. Neurosurg Focus 2007;22(6):E6

32 Kuntz C IV, Blake L, Britz G, et al. Magnetic resonance neurography of peripheral nerve lesions in the lower extremity. Neurosurgery 1996;39(4):750-756, discussion 756-757

33 Cage TA, Yuh EL, Hou SW, et al. Visualization of nerve fibers and their relationship to peripheral nerve tumors by diffusion tensor imaging. Neurosurg Focus 2015;39(3):E16

34 Stoll G, Bendszus M, Perez J, Pham M. Magnetic resonance imaging of the peripheral nervous system. J Neurol 2009;256(7):1043-1051

35 Li CS, Huang GS, Wu HD, et al. Differentiation of soft tissue benign and malignant peripheral nerve sheath tumors with magnetic resonance imaging. Clin Imaging 2008;32(2):121-127

36 Chhabra A, Thakkar RS, Andreisek G, et al. Anatomic MR imaging and functional diffusion tensor imaging of peripheral nerve tumors and tumorlike conditions. AJNR Am J Neuroradiol 2013;34(4):802-807

37 Yuh EL, Jain Palrecha S, Lagemann GM, et al. Diffusivity measurements differentiate benign from malignant lesions in patients with peripheral neuropathy or plexopathy. AJNR Am J Neuroradiol 2015;36(1):202-209
38 Yamasaki F, Kurisu K, Satoh K, et al. Apparent diffusion coefficient of human brain tumors at MR imaging. Radiology 2005;235(3):985-991

39 Nagata S, Nishimura H, Uchida M, et al. Diffusion-weighted imaging of soft tissue tumors: usefulness of the apparent diffusion coefficient for differential diagnosis. Radiat Med 2008;26(5):287-295

40 Russell SM. Preserve the nerve: microsurgical resection of peripheral nerve sheath tumors. Neurosurgery 2007;61(3, Suppl):113-117, discussion $117-118$

41 Safaee M, Parsa AT, Barbaro NM, et al. Association of tumor location, extent of resection, and neurofibromatosis status with clinical outcomes for 221 spinal nerve sheath tumors. Neurosurg Focus 2015;39(2):E5

42 Maniker AH. Diagnostic steps, imaging, and electrophysiology Neurosurg Clin N Am 2004;15(2):133-144, v

43 Ball JR, Biggs MT. Operative steps in management of benign nerve sheath tumors. Neurosurg Focus 2007;22(6):E7

44 Kline DG, Judice DJ. Operative management of selected brachial plexus lesions. J Neurosurg 1983;58(5):631-649

45 Arviso LC, Johns MM III, Mathison CC, Klein AM. Long-term outcomes of injection laryngoplasty in patients with potentially recoverable vocal fold paralysis. Laryngoscope 2010;120(11):2237-2240

46 Katz AD, Passy V, Kaplan L. Neurogenous neoplasms of major nerves of face and neck. Arch Surg 1971;103(1):51-56

47 Brandenburg JH. Neurogenic tumors of the parapharyngeal space. Laryngoscope 1972;82(7):1292-1305

48 Maisel RH, Ogura JH. Neurofibromatosis with laryngeal involvement. Laryngoscope 1974;84(1):132-140

49 Andrioli G, Rigobello L, Mingrino S, Toso V. Tapia's syndrome caused by a neurofibroma of the hypoglossal and vagus nerves: case report. J Neurosurg 1980;52(5):730-732

50 Kuniak B, Strelka J. Malignant neurofibroma of the cervical portion of the vagus nerve [in Slovak]. Cesk Otolaryngol 1990;39(5):313-317

51 Shimizu H, Yoshihara T, Sakurai H, Nozaki M. Cervical neurofibroma in a patient with von Recklinghausen's disease. Auris Nasus Larynx 1994;21(4):253-257

52 Fujino K, Shinohara K, Aoki M, Hashimoto K, Omori K. Intracapsular enucleation of vagus nerve-originated tumors for preservation of neural function. Otolaryngol Head Neck Surg 2000;123(3):334-336

53 Ilgner J, Rojas W, Biesterfeld S, Schürmann K, Zimny M, Westhofen M. Low-grade malignant peripheral nerve sheath tumor of the neck soft tissues [in German]. Laryngorhinootologie 2001;80(1):39-42

54 Ozcan M, Tuncel U, Unal A, Erdogan A, Han O, Nalca Y. Concomitant vagal neurofibroma and aplasia of the internal carotid artery in neurofibromatosis type 1. Ear Nose Throat J 2001;80(10): 730-732, 734, 737

55 Kuzu Y, Beppu T, Sibanai K, Ogasawara K, Ogawa A, Kurose A. A case of malignant peripheral nerve sheath tumor originating from the cervical vagus nerve [in Japanese]. No Shinkei Geka 2002; 30(5):523-526

56 Cihangiroglu M, Yilmaz S, Topsakal C, Gok U, Altinsoy B, Cobanoglu B. Laryngeal neurofibroma associated with neurofibromatosis type 2. AJNR Am J Neuroradiol 2002;23(10):1637-1639

57 Molina AR, Brasch H, Tan ST. Malignant peripheral nerve sheath tumour of the cervical vagus nerve in a neurofibromatosis type 1 patient. J Plast Reconstr Aesthet Surg 2006;59(12):1458-1462

58 Matejcik V, Steno J, Haviarova Z, Mravec B. Neurofibroma of the vagus nerve in the cervical portion. Bratisl Lek Listy (Tlacene Vyd) 2008;109(10):455-458

59 Guler AK, Gunaldi O, Alis H, Tugcu B, Tanriverdi O, Colluoglu B. Cervical segment nervus vagus neurofibroma with associated neurofibromatosis type 1: a case report. Minim Invasive Neurosurg 2009;52(5-6):246-249

60 Sesenna E, Magri AS, Corradi D, Ferri T, Ferri A. Malignant peripheral nerve sheath tumor of the vagus nerve in a teenager with the neurofibromatosis 1 gene mutation: a case report. J Pediatr Surg 2011;46(8):e9-e12

61 Yazar O, Topal H, Streukens S. A painless neck swelling and von Recklinghausen. Acta Chir Belg 2014;114(1):84-86 